\title{
HUMANITIES
}

\section{Full code}

667 f your heart and lungs stop working while you're in hospital, what would you like us to do?'

"Everything."

"Drugs to push your heart along?"

"Yes."

"Breathing tube?"

"Yes."

"Thumping on your chest?"

"Yes."

"Everything." Still in my first weeks of clerkship, I thought my patients knew what "everything" meant. I thought I knew what "everything" meant. Now I know better.

\section{One}

Thump, thump, thump, thump.

"Who's next on CPR? Is someone keeping time?'

Creak, creak, creak, creak.

"Why don't we have IV access? Someone get the IO!"

A second's hesitation at the announcement left me stranded outside the room as a dozen people pushed in. Most, like me, were spectators, watching the dance within from behind jostling shoulders. A handful of people whirled around the patient: CPR, IVs, intubation. A freckled nursing student stood by the door, eyes wide. We stood together, waiting to be called upon - but we never were. A few physicians stood at the back of the room, arms crossed, and, on seeing the situation handled by others, continued with their clinical duties. They knew what we didn't: they couldn't change much.

"The patient has critical aortic stenosis. This is going to be more of an academic exercise."

And yet the team continued. With each compression, bloody secretions oscillated higher and higher in the tube. The man's eyes gaped open; I couldn't quite see his expression. Twenty minutes.

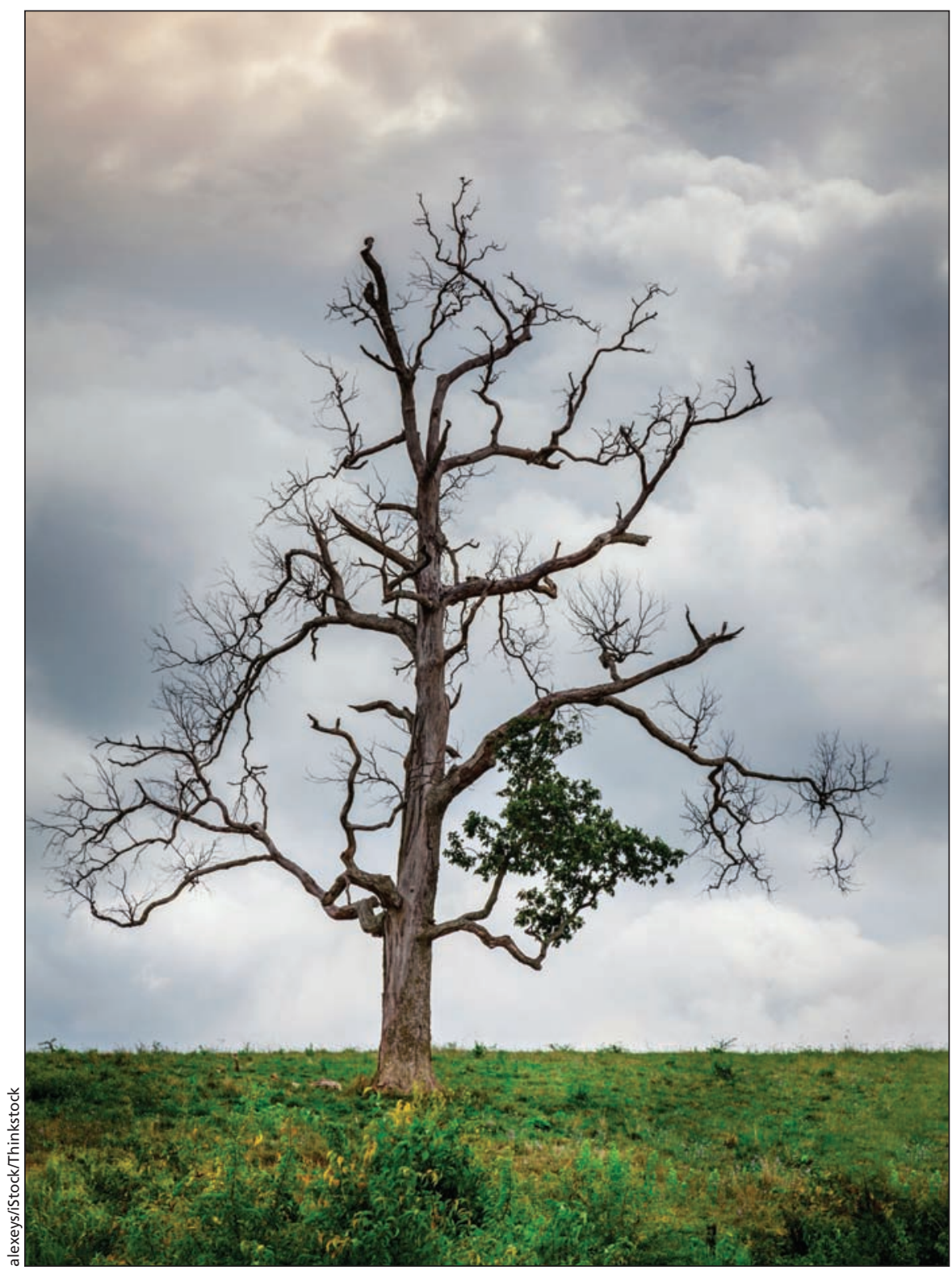

Another pulse check. Silence. Stillness. No rhythm.

"Time of death, 9:05." The chaos was over.

"Was that your first code?" a resident asked. "Good learning experience."

\section{Two}

Flip flip, rustle rustle, thump thump. I could hear my own heart beating of its own volition in my throat as the team struggled to keep the patient's heart going. What can we know about him? Heart failure. Widower. CAD. Accountant. Asthma. Two daughters. The snippets of a life contained in the pages of a green binder.

"What do we know about him?" The harsh call of the resident snapped me out of my reverie. I shouted back the medical history and the lab results from outside the room, peeking over the binder. The dance was beginning 
to take form: a series of gestures resolved into choreography. The timing. The compressions. The drugs.

"Someone notify the family." The aftermath.

\section{Three}

"I'm doing better, see! My breathing's much better. When do you think my next surgery will be?" He coughed, adjusted his nasal prongs and brushed thick brown hair out from behind the tubing. He was strong for an ICU patient, not having had time to waste away on a ventilator.

"I've heard later this week, but no promises. We'll see what they say today. It's a delicate balance."

"I've heard that one before."

He had no complaints, his vitals looked good. I wished him well for the surgeons' looming visit. He thanked me.

Later that day, while examining another patient, I heard a mumble from the PA: "Code blue, bay three."

I ran. One of the nurses was explaining, "I was just talking to him, and his eyes rolled back." From this point on, it was the fellow's show to run.

"Light compressions or you'll rupture the aneurysm, if it hasn't ruptured already!"

Kneeling on the bed, tentatively thumping on his chest, I tried not to look at his face, but I couldn't look away. His eyes were open, unblinking, dark circles seemed darker on his ashen face. The ICU fellow put a bronchoscope down the patient's throat, his hand resting on the patient's blood-streaked hair.

"Someone call vascular!"

"His belly's getting larger, firmer."

"Dammit."

The bronchoscope showed blood leaking into the patient's chest. With every compression, I was pushing the life out of him. But how could I not? Someone had to.

When his daughter and son-in-law came, the fellow told them what happened.

"It happens sometimes. The aneurysm exploded." And then the fellow was on to the next patient, continuing the duties of the ICU.

"Everything." I try to tailor the word now: not enough detail to frighten, but enough to communicate some sense of the cost of this choice.

The patient was unstable, but we had time. He was a young, 77, with a close family, and full code at that. The nurse hurried to get his family and the priest - from the waiting room. I was finishing some charting as the flock entered, all whispering anxiously in Italian. Then I heard a music breaking through the ticking and whirring of the ICU. Latin, I think. Though I couldn't quite make out the words.

\section{Lauren Elizabeth Gordon MSc}

Medical student

Schulich School of Medicine \& Dentistry

Western University

London, Ont.

Acknowledgements: The author thanks Dr. Michelle Levy, Dr. Raphael Rush and Julia Bolotina for their comments on drafts of this essay.

All characters in this work are fictitious. Any resemblance to real persons, living or dead, is purely coincidental.

CMAJ 2015. DOI:10.1503/cmaj.140435

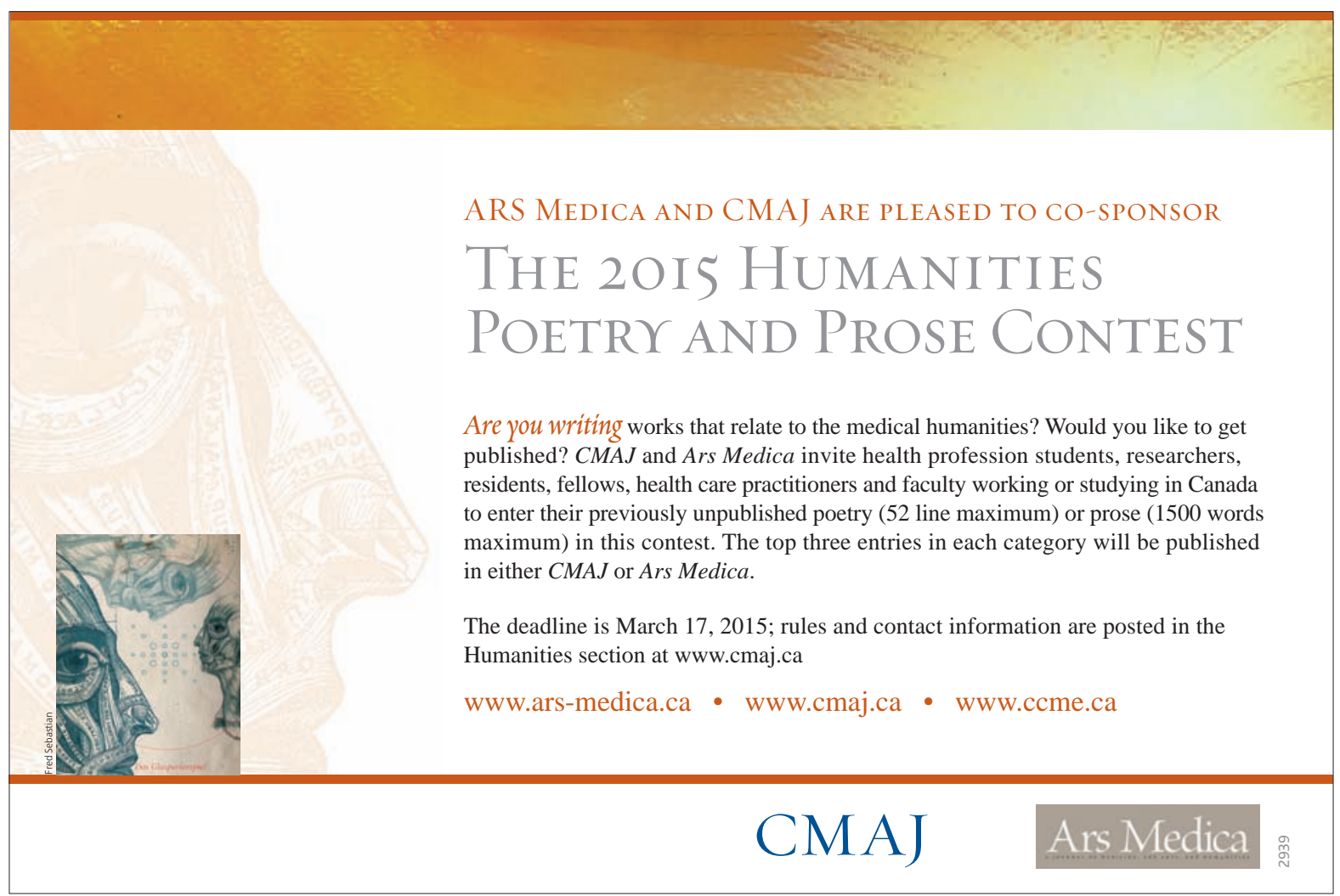

